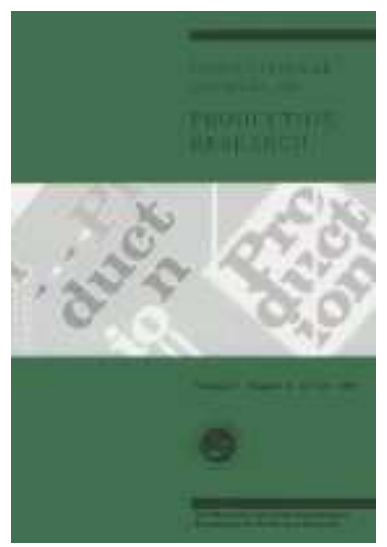

\title{
Managing Relationships to Improve Performance: A case study in the global aerospace industry
}

\begin{tabular}{|r|l|}
\hline Journal: & International Journal of Production Research \\
\hline Manuscript ID: & TPRS-2005-IJPR-0287.R1 \\
\hline Manuscript Type: & Original Manuscript \\
\hline Complete List of Authors: & $\begin{array}{l}\text { 11-Jan-2006 } \\
\text { Morton, Susan; Loughborough University, Wolson School of } \\
\text { Dainty, A R J; Loughborough University, Civil and Building } \\
\text { Engineering } \\
\text { Burns, N D; Loughborough University, Wolfson School of Mech and } \\
\text { Man Engineering } \\
\text { Brookes, Naomi J; Cranfield University, Advanced Management } \\
\text { Research Centre } \\
\text { Backhouse, C J; Loughborough University, Dean of the Faculty of } \\
\text { Engineering }\end{array}$ \\
\hline Keywords (user): & improving performance, social network analysis \\
\hline KUMAN RESOURCE MANAGEMENT, PRODUCT DEVELOPMENT \\
\hline
\end{tabular}

\section{scholarONE" \\ Manuscript Central}




\begin{abstract}
Organizations wishing to succeed in the competitive climate of the contemporary marketplace will need to differentiate themselves from competitors. World class product development is considered the key to competitive advantage and, to compete effectively in global markets, organizations need to be proficient at this core activity. The knowledge-intensive process of product development will benefit from strategic alliances with customers based on trust and mutual benefit. This paper reports on research which developed a managerial tool that allows manufacturing organizations to understand the impacts of relationships at the boundaries of their internal and external activities. It focuses upon the importance of collaboration to forming and maintaining productive relationships within and between organizations. Such an approach will help organizations, and the individuals within them, to identify appropriate internal and inter-organizational network development strategies. An important assumption that underlies its development is that the model will improve project and product development performance by improving communication flows through enhanced networked relationships between team members, and hence improve the overall performance of the organization. This paper sets the research context and presents results of action research with a team of engineers from a large organization in the aerospace industry. It reveals the crucial importance of trust in underpinning successful internal and inter-organizational relationships. It is suggested that the tool provides a convenient methodology for measuring and benchmarking relational network performance.
\end{abstract}




\section{Introduction}

Manufacturing quality and efficiency alone are deemed insufficient differentiators in determining organizational competitive edge, with "major opportunities for wealth creation [coming] from new products, processes and product/service combinations" (Foresight Manufacturing Panel 2000). Increasing competition in a global marketplace necessitates the strengthening of organizational product development capabilities. The introduction of new technologies is further fragmenting global markets and emphasis is placed on organizations to address such issues by formulating a clear product development strategy that takes account of how best to integrate technological change (Wheelwright and Clark 1992; Hayes et al. 2005). World class product development is the key to competitive advantage within global markets and so organizations need to be proficient at this core activity (Erhorn and Stark 1994).

Given that people are the key to success, manufacturing organizations will be expected to encourage and sustain a work culture that uses an individual's skills to maximum effect whilst supporting the experiential learning that will give employees the skills to manage processes and improve performance. The purpose of this research is to provide manufacturing organizations with a practicable tool that can be used to manage performance by improving communication flows through enhanced relationships between teams, departments, organizations and strategic supply chain alliances. The tool facilitates the visualisation of personal networks and their efficacy, thereby enabling individuals and teams to develop strategies for managing relationships more effectively in a bid to improve organizational performance.

The research utilises Social Network Analysis techniques (c.f. Tichy et al. 1979, Wasserman et al. 1994) within a standardised structure to facilitate comparative analysis of industrial partners. Structured/semi-structured questionnaires are employed, together with individual interviews, workshops, and stage reviews. This demonstrates the practical utility of this approach through action conducted within a large organization in the aerospace industry.

\section{Social Networks as a Route to Performance Improvement}

Smart et al (2000) determined the feasibility of a 'boundary-based' approach to organizing human resources during product development. This perspective stresses the need for firms to not only consider the strategic placement of formal organizational boundaries, but also the concurrent development of innovative options for overcoming them. Their findings confirm the importance of network organization theory in the development of future competitive product development strategy. Furthermore, some important grounded theoretical developments focussed on their identification of an important mechanism - the informal organization used to overcome formal organization boundaries.

Research over the last decade has shown that the informal organizational network of interrelationships is used for resource exchange, cutting across formal boundaries, and avoiding barriers and lengthy delays generated by the prescriptive processes of the formal structure (eg Newell, Swan et al. 1998; Liedtka, Haskins et al. 1999; Athaide and Stump 1999; Mintzberg and Van der Heyden 1999; Smart, Brookes et al. 2002). Alongside the work-related sources of technical advice, for example, the informal network also comes into play for transmitting the social support and social norms related to the organization (Pagel et al. 1987; Podolny and Baron 
1997; Inkpen and Tsang 2005). However, this same mechanism can also be used to block communication, obstruct innovation, foster negativity and delay, or even halt change (Brass 1984, Krackhardt and Hanson 1993, Podolny and Baron 1997). Workbased social interaction has traditionally been viewed as falling into this latter category. Thus, the restructuring of organizations has taken place in an environment wary of these negative aspects and has taken little account of positive features.

\subsection{Strategies for change}

Organizations have traditionally been predominantly vertical structures, with working environments characterised by a lack of flexibility, co-ordination and integration between the different functional departments. The last few decades has witnessed a move from the functionally-based formal structure in organizations through phases of matrix, team-based and networked structures to more closely resembling Wenger's communities of practice model (Wenger and Snyder 2000).

Reconstruction of the formal organization over this period has not happened in isolation. It has taken place in an environment of change to the basis of competition in the global marketplace and within the context of a plethora of change management programmes (Total Quality Management, Concurrent Engineering, Business Process Re-engineering, Knowledge Management and Platform Engineering, for example). Henderson (1994) suggests, however, that the search for an optimal organizational form is a fruitless exercise, emphasising that "success is not a function of a particular organizational choice". Irrespective of its formal structure, "for an organization to be truly effective, each part of it must work properly together towards the same goals, recognizing that each person and each activity affects and in turn is affected by others" (Oakland and Porter 1996). Indeed, Henderson (ibid.) found that much of the real work in organizations happens despite the formal structure. The informal organization often circumvents formal organizational structures whereby a single piece of communication can move through parts of the structure whilst circumventing others, thereby undermining the formal communication protocols of the organization (Dingle 1997). Such a perspective questions the primacy of purely structural solutions to organizational performance improvement, placing an emphasis on the inexorable but complex relationship between human interaction and business development.

Research in the automotive industry supports the value and importance of informal communication in product development. Smart et al's (2000) ethnographic study of an automotive manufacturing organization found the consistent presence of informal interrelationships between product developers. This presence continued independent of three major, and several minor, changes to the formal organizational structure implemented over a period of twenty years - evidence of Krackhardt and Hanson's informal organizational network (Krackhardt and Hanson 1993).

Concurrent engineering also recognises the value of informal communication in product development and co-locates project team members to facilitate a positive environment for more rapid exchange of ideas and information (Jo et al. 1991; Syan 1994; Backhouse and Brookes 1996). Nevertheless, the expertise that made project team members attractive in the first place can be diluted over lengthy periods of collocation (Anumba et al. 2000). Managing product/project design and development activities successfully may simply mean allowing individuals to use their own networks. Indeed, providing individuals with the skills and opportunities to enhance 
their own networks of relationships in different directions across the formal organizational chart (Smart, Brookes et al. 2001).

Traditional charts show the hierarchy of an organization and are considered a poor representation of who is interacting with whom, and who may have the power in an organization. Extant research has emphasised the inadequacy of the formal structure in explaining an organization's behaviour, and the impact of informal organizational networks upon it (Foy 1980; Handy 1993; Krackhardt 1993; and Nohria and Eccles 1992). Mintzberg and Van der Heyden (1999) found organigraphs more useful than traditional charts in showing what an organization is, why it exists and what it does. Organigraphs are overview maps that "demonstrate how a place works, depicting critical interactions among people, products, and information ... pictures that show not headaches but real businesses and their opportunities". They provide insights into the social interactions between the people, otherwise known as the social capital of the organization (Mintzberg and Van der Heyden 1999).

\subsection{Social capital of organizations}

Organizational capital has been viewed as comprising the elements of financial, human, and social capital, where the social capital of individuals aggregates to the social capital of the organization (Burt in Nohria and Eccles 1992). Social capital has been considered the constituent that bonds individuals to each other (Stephenson 1998) and to the organization (Baker 2001). Bouty's investigation into the exchange of strategic resources across organizational boundaries found social capital to be the key success factor for organizational development performance (Bouty 2000). Cohen and Prusak's text on social capital provides explanation that identifies the importance of trust in its construction. "Social capital consists of the stock of active connections among people: the trust, mutual understanding, and shared values and behaviors that bind the members of human networks and communities and make cooperative action possible" (Cohen and Prusak 2001). Thus, the degree of trust that exists between members of an organization can be used as an indicator of the level of social capital that an organization possesses (Knack and Keefer 2000).

\subsection{The concept of trust in relationships}

Trust is a very complex construct, with multiple levels, different bases, and determinants (Rousseau et al. 1998). While the word is well known, and frequently believed to be understood, trust has been defined in many different ways (Williamson 1993; Zucker 1986; Rotter 1967). The main point that researchers on trust might agree on is that there is no common agreement about the concepts and definitions of trust (Möllering 2003).

In order for people to be willing to share their knowledge, for example, they must have trust (Davenport and Prusak 1998; Podolny and Baron 1997; Kramer 1999). More specifically, trust is a prerequisite for tacit knowledge sharing (Roberts 2000, Rolland and Chauvel 2000). The importance of trust in successful relationships is further highlighted by Bouty (2000), Athaide and Stump (1999), and the longitudinal study of an automobile manufacturer (Brookes 2001, Smart 2002, Morton 2002). Trust is also considered a key factor in effective supply chain management and, while it does not lend itself easily to measurement, the value of trust can be measured in terms of lower costs, added value and the encouragement of resource sharing (Landry 1998). 
Trust is a concept that has received much attention in the management literature too, exemplified by the work of Meyerson et al. (1996), Hardt and Brynteson (1999), Jarvenpaa (1998; 2001), Lewis and Weigert (1985), Lyon (2000), and Newton (2001). Jarvenpaa's work is of particular relevance in its investigation of trust in the context of a boundaryless network (Jarvenpaa, Knoll et al. 1998). So too is the growing body of research on swift trust: exemplified by that of Meyerson et al. (1996), Jarvenpaa and Leidner (1997, 1999); Hardt and Brynteson (1999); and Jarvenpaa and Staples (2001), amongst others. The concept of swift trust has developed to explain behaviours in face-to-face temporary teams with no time to grow trust in gradual/cumulative fashion Markus (1994). Swift trust exhibits less emphasis on feeling, commitment and/or exchange and more emphasis on action, where action strengthens, and is both an important antecedent and outcome of, trust. McKenzie (2001) suggests that lack of interactive communication between employees, and between employees and the supply chain, inhibits the development of trust in relationships. The importance of respect as a concept was highlighted by the UK automobile manufacturer study, albeit not as well developed in the literature as trust. Respect is a conceptual term that has not undergone the same degree of exploration, although its importance in effective operations has begun to be considered, particularly in the context of 'turnarounds' (Kanter 2003).

A review of Smart's work (2001) also shows that informal relationships between product developers crossed formally prescribed boundaries and were observed as a means of repositioning the rigid formal boundaries that hinder the efficient and effective flow of information, ideas, knowledge and experience. The informal organization network presents connections that overlay and co-exist with the traditional formal organizational chart to take advantage of each of the other's strengths and overcome inherent weaknesses. The strengths of the informal organization also include, for example, the discovery of informal advice, trust and communication networks and relationships critical for improvements in product development performance (Krackhardt and Hansen, 1993; Baker 2001).

\subsection{Harnessing the informal organization}

The informal organization's capacity for change and managing change is immense, hence its suitability for pursuing product development in the dynamic market environment. It has structural characteristics that delineate a high degree of integration across formal organizational boundaries. These characteristics can be pictorially represented, drawing from social network analysis mapping techniques to present network patterns of relationships (Wasserman et al. 1994). Integration occurs via different types of relationships and formal boundaries, which may be strong or weak. Existing theories consider the concept of integration across vertical, horizontal and spatial boundaries (Lawrence and Lorsch 1967, Nohria and Eccles 1992). More recently, Smart (2002) has also shown the importance of integration being viewed across time boundaries, particularly apparent when informal relationships are reported to have survived many changes to the formal organization structure over time. Further, such relationships remain intact even when product developers no longer work within the same organization.

Despite a move to the conceptualisation and understanding of more creative forms of formulating strategy - utilising the informal organization, for example organizations continue along the traditional planning, design and positioning route in product development (Frost 2003). Nevertheless, research suggests significant 
disparities in the way that companies organize for success, with successful organizations being more relationship driven. An emergent model of success is the Relationship-Centric organization: "a networked, agile and highly adaptive entity that transcends traditional boundaries as it develops deep and collaborative relationships internally as well as with customers, suppliers, alliance partners, and, increasingly competitors" (Neilson, Gulati et al. 2004). This review has provided some indication of the strategic strength of the informal network of interrelationships in such relationship-centric organizations. Raising awareness of that strength and developing a mechanism for harnessing it to improve product development and hence organizational performance are the prime motivators for the current research.

\section{Social Networks in the Aerospace Sector: A Case Study}

The component supplier base in the aerospace industry has historically been highly fragmented. First tier supplier status is becoming increasingly important and the trend is towards the procurement of systems or integrated products from strong, capable supplier companies. Integral with this trend has been a move by aircraft prime contractors and systems integrators to outsource structural and component production and focus more tightly on their core activities (Tutton 2003).

The shift is towards first tier suppliers building long term relationships with customers and servicing their needs around a manufactured product. Successful businesses will be those that develop and maintain strategic alliances with customers based on trust and mutual benefit: alliances that extend beyond sales to affect research and development, innovation, new product introduction and continuous product development. The knowledge-intensive process of product development will benefit from such alliances, with extended networks of specialists working together effectively, cutting across the inherent boundaries of internal and inter-organizational formal structures thus reducing development time and costs.

Company A is a global independent first tier supplier of structures, components, assemblies and engineering services to aircraft and aero engine manufacturers. The organization's aim to provide excellent and continuously improving products and services underpins the tactical business unit that supports the strategic alliances with its customers and suppliers. Situated within one arm of this business area, the case study subjects form the Company A part of an interorganizational project team of engineers engaged with the customer organization in continuous improvement to and further development of core business product.

\section{Research methodology}

Given the complex nature of manufacturing organizations and product development undergoing change, a case study approach is highly appropriate. This approach is thought to overcome the bias inherent in a single method approach (Gill and Johnson 1991). It is particularly useful when the research phenomenon is not easily distinguishable from its context (Yin 1993). It also helps to isolate individuals and organizations to study their situation in greater detail, affording an accurate understanding of the experiences, perceptions and interactions between those involved in product development and the way this affects its success. Moreover, given Yin stresses that the importance of case study research is to generalise to theory and not to the wider population (Yin 2003), case studies also provide detailed, rich and often anecdotal accounts of complex events and situations. 
In order to map the social network of the case study organization, individuals needed to be asked about very personal aspects of their relationships with their colleagues. The main concern, therefore, was that investigation subjects might not reply honestly to the questions asked due to concerns that their opinions would be communicated to particular individuals, and perceptions that the exercise might form part of some management agenda to rate the abilities of employees within the network. In order to negate such effects a data collection process was employed that emphasised confidentiality, whilst ensuring that organizational commitment to all stages of the process was clearly visible and documented (Clark and Wheelwright 1995). A clear purpose for use of the model and how its results would be used was also communicated to all participants at the start (Argyris 1962, Hardt and Brynteson, 1999). Further, the researcher as facilitator was external to the organization to maintain confidentiality of data subjects' personal information (Svenke and Goslinga 2003). Opportunities were also provided to ensure the building of trust between the research subjects and the facilitator, particularly at the start of the process (Herzog 2001), through self/team perception tasks and team-building activities, for example. Thus, the first stage of the data collection process took place within a one-day workshop event that focused initially upon trust building and information gathering, followed by review and discussion of the resultant data.

The event began with a formal introduction to the activities explaining how information would be used, and which stressed the confidentiality of individual responses and the separate affiliation of the activity from any other management agenda. Each individual was subsequently provided with an A4 duplicated pro-forma on which to record their data, and asked to return the top copy directly to the research investigator for in-situ compilation of the team network and later analysis. The proforma uses relationships with individuals during the product development process as its unit of analysis. Subjects were asked to identify individuals with whom they interacted during product development, to locate each contact in relation to stakeholder category and to rate each relationship in terms of the level of trust and the success of interaction in transferring required information and resources. It may be argued that the measurement of interaction made by participant team members on the trust and success embedded in the relationships could have been better achieved through the logic of 'domain sampling' (Judd et al. 1991), using multiple- rather than single item constructs. The implications are that measures with more items are more reliable (Nunnally 1978). In pilot investigations, however, ratings from single-item and multiple-item responses correlated significantly, which gave the researcher confidence to only use single item in the final approach to social network analysis. Team members were also asked to self-rate the level of trust and the interaction success of their relationships. Although self-ratings would not normally be utilised without some 'objective' confirmatory rating, in this case it was necessary to rely on self-rating alone. Interaction success and level of trust are subjective concepts necessarily rooted in the self-perception of the team member.

Pro-forma top copy data were collated and an anonymised draft map of team interrelationships produced to provide the visual focus for discussion in the workshop activity. Subjects retained the 2nd copy to complete anonymised graphical A1 versions of their personal network for in-situ display and initial whole-group visual analysis. This data collection process would be difficult to replicate in organizations that did not have the openness of culture exhibited by that of the research population. After an agreed interval, the survey instrument was later sent electronically as a 
follow up activity. Each subject received a copy of the questionnaire, personalised with the list of contacts they had provided in the workshop, together with their earlier ratings for trust and interaction success. Each subject was asked to further provide information for each contact in terms of ratings for respect and loyalty (as components of trust), details of the relationship's age, the degree to which that person had a similar background and whether the relationship had a context outside the work environment, for example. The findings from this second stage of data collection will be the subject of further analysis and the implications reported upon in subsequent papers.

\section{Results}

\subsection{Research Findings}

The social network emerging within the case study organization was modelled by drawing from the graphical display methods of Social Network Analysis techniques to provide a snapshot of the team's internal and inter- organizational relationships. The draft snapshot was used as a catalyst for discussion in the afternoon activity of the workshop event described earlier. The combination of colour and linewidth was used to enhance the in-situ display of individual rankings for trust and success, respectively, in the team's network and to facilitate easy recognition, understanding, and awareness of content. Figure 1 demonstrates the network notation used. Numerically/alphabetically annotated network nodes represent individuals in the network and the lines show relationships between those individuals. The shape of the nodes indicates the stakeholder group to which the individual belongs and the internal/external nature of the relationship. Thus in figure 1 oval nodes represent respondents, circles represent individuals external to the respondent team but internal to the case study organization, and squares represent nodes external to the case study organization and within the customer organization. Network hubs are nodes that are cited by more than two respondents. The direction of the arrows indicates who has identified and rated the relationship: the arrow points in the direction of the individual identified. The thickness of the line indicates the success of product development related interactions in that relationship: the thicker the line the greater the level of successful interaction. In the absence of colour for the current medium, numeric annotation adjacent to the directional arrows is used to allow for the depiction of the individual measures for trust: the higher the number, the greater the perceived level of trust in the relationship. 


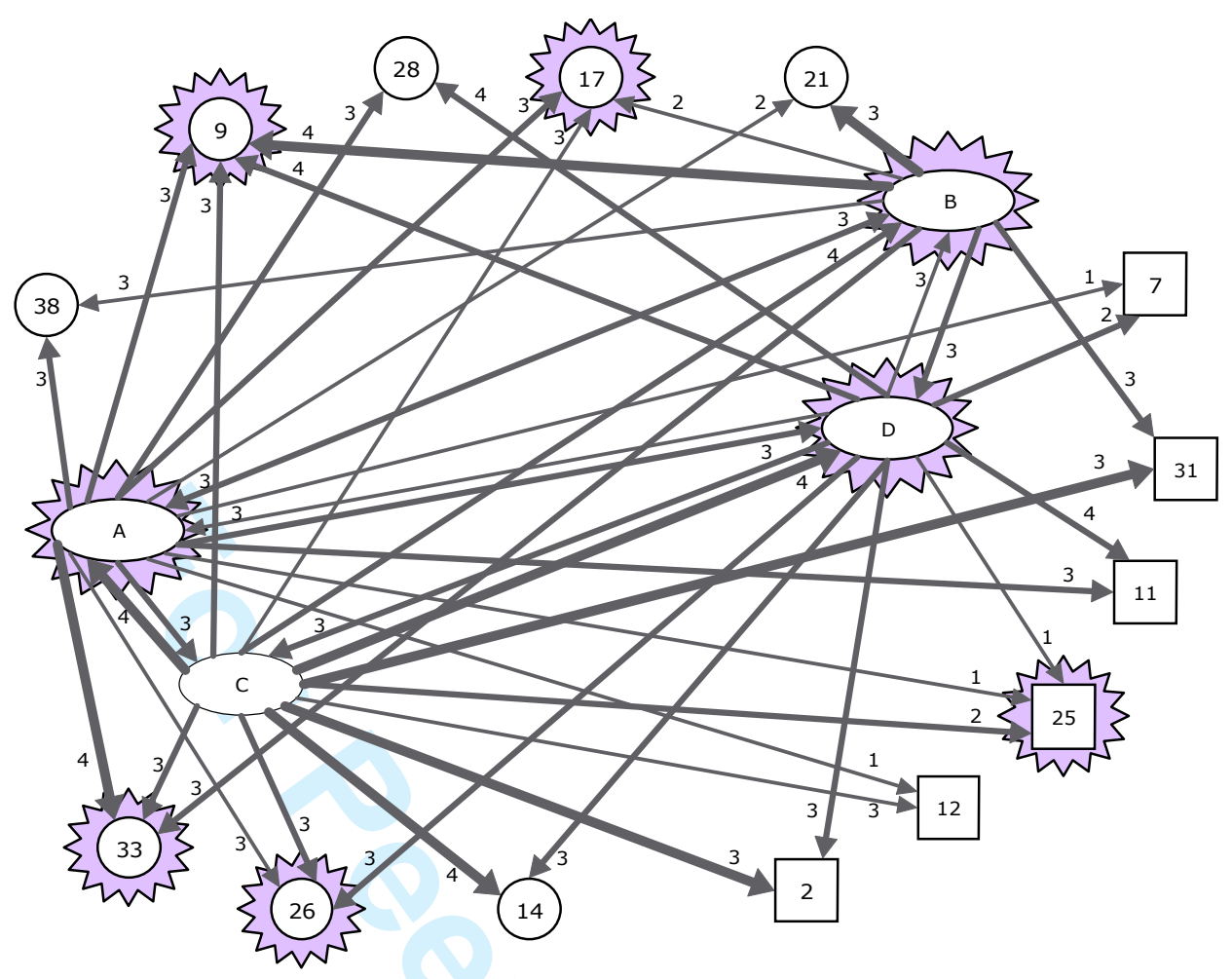

Figure 1. Case study network topology

While adhering strictly to the agreed policy on personal network confidentiality, the visual display of two example network maps, together with a brief review of the associated implications and issues that had arisen from investigation of each example, were provided during the workshop. The draft network map for the current team was subsequently shown and the team invited to comment upon its content, based upon the acquired knowledge and understanding gained from facilitated examination of the earlier examples. The ensuing discussion enabled the team to gain an appreciation of the relationships:

- internal to the current team

- external to the current team and internal to the organization

- external to the current team and external to the organization (ie customer contacts)

Further, the team was able to identify from the map where the internal relationships of the team, and the relationships of the team with others in the organization, were all fairly strong. This was evidenced by high measures for trust and success within the network diagram. However, the team also recognised that relationships with some of the customer contacts were of concern, ie relationships with low rankings for trust and success: for example, those of respondents C, A and D for node number 25; and A and $\mathrm{D}$ for node 7 in Figure 1. Team members also identified diversity in perception for some of the relationships with mutual contacts: for example, respondents A and B for node 21; and $\mathrm{C}$ and $\mathrm{A}$ for node 12. Such difference in perception for mutual relationships was found to be a key feature of network topologies, providing a further catalyst for discussion and the potential for improving relationships. 
Despite some apparently strong and reportedly successful links with the customer, the team perceived the project's inter-organizational relationship as fairly poor overall. Causal factors were identified as a lack of high quality communication channels between the team and external organizations. Further causes included the personality of individuals, inter-organizational politics, fear of change, and the fear of the possible devolution of work from customer organization to that of Company A, the supplier organization, and its potential impact on livelihood. Further discussion centred on investigation of how the paucity of the inter-organizational relationship overall could be improved. Poor individual relationships and the differences in perception of the team for certain customer contacts were identified as a focus for further investigation.

While anonymity had enabled discussions to flow freely, the team agreed that any targeting of improvements would require some revelation, ie the team wanted the names of customer contacts from its own map to be revealed. As this was perceived not to compromise confidentiality from the data owners' point of view - ie the team members - customer contact names were provided. Issues and differences in relationships with customer contacts were subsequently identified and the team members began to identify themselves on the social network map. This information enabled a dialogue around the development of an action plan for improving interorganizational relationships. The team agreed that access to and an understanding of the team's network map could help when it comes to expanding the team and that mapping would be useful for new team members who could be placed with a sympathetic team member. Further, for the relationships that were clearly identified as problematic, the team should focus development and interventions using the more positive individual relationships. It was also agreed that the team should get together as a follow up to the event and look at the ways forward in improving relationships and hence team/organizational performance. The immediate line manager and more senior manager of the team also agreed to help new people coming in to the Company A side of the team to steer away from the negative aspects of the inter-organizational relationship and to target the more positive aspects. Additionally, to support the focus on the more positive network links as the liaison in work-related activities and to investigate involving the customer organization.

\subsection{Practical utility of the model}

A measure of the efficacy of the insights gained from application of social network mapping and analysis in the case study organization was obtained by interviewing Senior Management of the Company A team, and by interviewing a sample of representatives from the customer organization. Customer representatives were asked whether, and how, they thought relationships with the team had improved over the past six months. Level of trust was reportedly "pretty high ... and quite successful really ... definitely grown". Indeed, improved success was considered to have resulted from having a stronger and better-defined team. Moreover, positive feedback was also gained in relation to continuity: "we deal with the same people ... relationships help get things done".

The Senior Manager expressed his response in terms of the gain to strategic capability from using social network analysis with the team. Specifically, it was reported that interactive participation in the research helped the organization to implement business strategy, whereas the previous level of relationship with the customer was such that it would not have supported such activity. In terms of building 
new types of relationships with the customer, he reported "we've been able to significantly develop the relationship and build it to a level where we're doing more conceptual engineering work for [the customer]", emphasising "the things we've done [with SNA and the research team] have been fundamental to us enacting that strategy and that route forward".

'Action research' application with the case study team enabled visualisation of the team's network and the mapping of network discontinuities to aid managerial decision-making. This approach has the potential to act, not only as a research tool, but also as a diagnosis tool and catalyst for change. Industrialists within and external to the case study organization could use the approach when developing their own teams, diagnosing team performance and dealing with intra-team conflicts, for example.

\section{Conclusions and further research}

The findings support the assumption that, for the case study organization, a managerial tool can be used to improve performance by improving communication flows through enhanced relationships between teams, departments, organizations and strategic alliances. The question must be addressed as to how far the findings can be generalised from this case study to product development activity in other contexts. This research was carried out in an enlightened organization: the same access to product developers over such sensitive issues may not be forthcoming in every environment. However, the methodology remains an effective way of exploring the strength of relational networks and hence, could provide a transferable approach within other organizations. A second point to note is that product development in the case study organization was a technically challenging and complex activity. The importance of enhancing social capital through successful relationships to improve flows of information may be reduced where product development is less complex.

Previous work reported earlier has indicated that organizational solution to improving product development should not be confined to alterations to formal structural units. Attempts to improve must also take into account the importance of the network of relationships that create the social capital of the product development activity. The research with Company A provided opportunity for longitudinal review of the case study team's network of interrelationships, and of the impact upon the overall organization from participation in the research and application of the managerial tool.

The research identified differences in perception as being crucial to the investigation. Contrary to what may be considered a desirable outcome, it is not necessary to have hard measures to bring varying perceptions into line. Perceptions are highly personal and are what informs the whole process. Mapping the perceptions as network topologies is the means for identifying potential problems and identifying ways forward, ie the network map is a catalyst for discussion rather than being an end in itself. The case study subjects concluded that the snapshot visualisation of the team network provided a 'good focus' for the investigation of issues and problem relationships in a non-threatening environment. The anonymity of the map enabled the team to identify problems without 'pressure', which was only later followed by a consensus for 'revelations' to be made and enable the map to be used as the key focus for action planning. The team later reported that the agreed strategy and action plans had been put into effect with positive results. Internal and external relationships were 
showing signs of improvement and the team reported that inter-organizational relationships were more effective in terms of project outcomes. Interviews with customer representatives provided confirmation of the improvement to the interorganizational relationships. For example, customer representatives were asked whether relationships had changed and how they would rate the strength of those relationships in terms of the levels of interaction success and trust in those relationships. The overall picture that these interviews presented was of growing and high levels of satisfaction with the team subsequent to the work undertaken by the research team and the application of the social network analysis model.

The overall benefits that had accrued from participation in the case study research were summarised by Company A's senior management in terms of the organizational capability to measure trust and co-operation, to identify key players and to exploit strategic contacts. Participation also helped to kick-start team building: enabling the individuals to come together and identify/understand the relationships with each other, and with the customer, at an early stage of the project, proved of benefit in terms of raising the team's awareness of issues and potential problems. It further enabled easier integration of new team members and pinpointed the gaps in the network and in the skills of team members. Furthermore, use of the tool enabled the organization to predict problems before they happen and, not least, to improve relationships with alliance partners. Thus the information gleaned from participation in the case study research helped the organization to foster better team relations and stronger intra- and inter-organizational networks.

It was further reported that additional skills are now being sought in the selection of team leaders. A benchmarking exercise is also being developed and short to medium term team, project and organization-wide plans are under development as a result of the research activities. Such actions provide evidence that Company A exploited, or harnessed the power of, the informal organization to improve the internal and inter-organizational communication flows through enhanced network relationships between team members, and hence improve product development performance. Further support is evidenced by plans for the subsequent investigation into how networking knowledge might be integrated into the everyday business of the organization, how network performance might be regularly assessed, and how the lessons learned might be spread throughout the organization. These and other such questions will also be used to inform further research within and external to the organization.

\section{References}

Anumba, C. J., Siemieniuch, C. E. and Sinclair, M. A. (2000). "Supply chain implications of concurrent engineering." International Journal of Physical Distribution \& Logistics Management 30, 7/8:556.

Argyris, C. (1962). Interpersonal Competence and Organizational Effectiveness. Tavistock Publications Limited, London.

Athaide, G. A. and Stump, R. L. (1999). "A Taxonomy of Relationship Approaches During Product Development in Technology Based, Industrial Markets." Journal of Product Innovation Management 16, :469 - 482.

Backhouse, C. J. and Brookes, N. J., Eds. (1996). Concurrent Engineering: What's working where. Design Council, Gower, 
Baker, W. (2001). "Social Capital: Help your people expand their networks." Executive Excellence Vol. 18, No. 8::p. 9.

Bouty, I. (2000). "Interpersonal and interaction influences on informal resource exchanges between R\&D researchers across organizational boundaries." Academy of Management Vol. 43, No. $1::$ pp. 50 - 65.

Brass, D. J. (1984). "Being in the right place: A structural analysis of individual influence in an organization.” Administrative Science Quarterly Vol. 26, :: pp 518 - 539.

Brookes, N. J., Smart, P. K. and Lettice, F. E. (2001). The Importance of Informal Networks to Effective Design Management. 13th International Conference on Engineering Design ICED 01, Design Research - Theories, Methodologies and Product Modelling, 21-23 Aug 2001, Glasgow UK:, Professional Engineering Publishing, London.

Clark, K. B. and Wheelwright, S. C. (1995). The Product Development Challenge: competing through speed, quality, and creativity. Harvard Business School Publishing, Boston.

Cohen, D. and Prusak, L. (2001). "How to Invest in Social Capital." Harvard Business Review Vol. 79, No. 6: pp. 86-97.

Davenport, T. and Prusak, L. (1998). Working Knowledge: How Organizations Manage What They Know. Harvard Business School Press, Boston, MA.

Dingle, R. (1997). Project Management: Orientation for Decision Makers. Arnold, London.

Erhorn, C. and Stark, J. (1994). Competing by Design: Creating value and market advantage in new product development. Essex Junction, VT: Oliver Wight Publications Inc: .

Foy, N. (1980). The Yin and Yang of Organisations. Grant McIntyre Limited,

Frost, F. (2003). "The use of strategic tools by small and medium sized enterprises: an Australasian study." Strategic Change, Jan/Feb.

Gill, J. and Johnson, P. (1991). Research Methods for Managers. Paul Chapman Publishing Ltd, London.

Handy, C. (1993). Understanding Organizations. Penguin, 4th ed., London.

Hardt, P. O. and Brynteson, R. (1999). Swift Trust, Concordia University St. Paul MN: .

Hayes, R., Pisano, G., Upton, D. and Wheelwright, S. (2005). Operations, Strategy, and Technology:Pursuing the Competitive Edge. John Wiley \& Sons, USA.

Henderson, R. (1994). "Managing innovation in the information age." Harvard Business Review Jan 1994, Reprint No 94105., .

Herzog, V. L. (2001). “Trust building on corporate collaborative project teams.” Professional Journal of Project Management 32, 1:28-37.

Inkpen, A. and Tsang, E. (2005). "Social capital, networks, and knowledge transfer." Academy of Management Review 30, 1:146-165.

Jarvenpaa, S. L., Knoll, K. and Leidner, D. E. (1998). "Is Anybody Out There? Antecedents of Trust in Global Virtual Teams." Journal of Management Information Systems Vol. 14, No. 4: pp. 29-64.

Jarvenpaa, S. L. and Leidner, D. E. (1997). Do You Read Me? The Development and Maintenance of Trust in Global Virtual Teams, INSEAD Working Papers 97/95/TM: .

Jarvenpaa, S. L. and Leidner, D. E. (1999). "Communication and trust in global virtual teams." Organization Science Vol. 10, No. 6: pp. 791-815.

Jarvenpaa, S. L. and Staples, D. S. (2001). "Exploring perceptions of organizational ownership of information and expertise." Journal of Management Information Systems, Print Media Subtitle: JMIS 18, 1:151-183. 
Jo, H. H., Parsaei, H. R. and Wong, J. P. (1991). "Concurrent Engineering: The Manufacturing Philosophy for the '90s." Computers \& Industrial Engineering Vol. 21, No. 14: pp. 35-39.

Judd, C., Smith, E. and Kidder, L. (1991). Research Methods in Social Relations. Holt, Rinehart and Winston, Academic Press.

Kanter, R. (2003). "Leadership and the Psychology of Turnarounds,." Harvard Business Review 81, 6:58.

Knack, S. and Keefer, P. (2000). "Does Social Capital have an Economic Payoff? A Cross Country Investigation.” The Quarterly Journal of Economics 112, 4:1251-1288.

Krackhardt, D. and Hanson, J. R. (1993). "Informal Networks: the company behind the chart." Harvard Business Review Vol. 71, No. 4: pp. 104-111.

Kramer, R. (1999). "Social uncertainty and collective paranoia in knowledge communities: Thinking and acting in the shadow of doubt". Shared Cognition in Organizations: The Management of Knowledge. L. Thompson, J. Levine and D. Messick. Mahwah, NJ, Lawrence Erlbaum Assoc. Publishers: 163-191.

Landry, J. T. (1998). “The Value of Trust.” Harvard Business Review Vol. 76, No. 1: pp. 1819.

Lawrence, P. R. and Lorsch, J. W. (1967). Organisation and Environment: Managing Differentiation and Integration. Harvard University,

Lewis, J. D. and Weigert, A. (1985). "Trust as a Social Reality.” Social Forces Vol. 63, No. 4: pp. 967-985.

Liedtka, J. M., Haskins, M. E., Rosenblum, J. W. and Weber, J. (1999). "The Generative Cycle: Linking Knowledge and Relationships.” IEEE Engineering Management Review Vol. 27, No. 1.

Lyon, F. (2000). "Trust, Networks and Norms: The Creation of Social Capital in Agricultural Economies in Ghana." World Development Vol. 28, No. 4: pp. 663-681.

Manufacturing 2020 Panel (2000). "Foresight: Making the future work for you". UK, Department of Trade and Industry: .

Markus, M. L. (1994). "Electronic mail as the medium of managerial choice." Organization Science 5, 4:502-527.

McKenzie, J. (2001). “Serving Suggestions.” Financial Management, Dec: p. 26.

Meyerson, D., Weick, K. E. and Kramer, R. M. (1996). "Swift Trust and Temporary Groups". Trust in Organisations. Thousand Oaks, Sage Publications.

Mintzberg, H. and Van der Heyden, L. (1999). "Organigraphs: Drawing How Companies Really Work." Harvard Business Review Vol. 77, No. 5: pp. 87-94.

Möllering, G. (2003). Ideal-types of trust and the role of suspension. Proceedings of the European Academy of Management, Track on trust, Milan, 3-5 April.

Morton, S. C., Smart, P. K., Brookes, N. J. and Lettice, F. E. (2002). From FTSE to KTSE Knowledge Through Social Exchange. European Operations Management Association 9th International Annual Conference: Operations Management and the New Economy, Copenhagen, Denmark, Copenhagen Business School, Aalborg University.

Neilson, G., Gulati, R. and Kletter, D. (2004). Organizing for Success in the 21st Century, Booz Allen Hamilton - Kellogg School of Management, Fortune 1000 Survey Findings, http://www.boozallen.com/bahng/SilverDemo. 2004: .

Newell, S., Swan, J. and Preston, J. (1998). Trust and Inter-organisational Networking. 14th EGOS colloquium, Maastricht. 
Newton, K. (2001). "Trust, Social Capital, Civil Society, and Democracy.” International Political Science Review Vol. 22, No. 2: pp. 201-214.

Nohria, N. and Eccles, R. G. (1992). Networks and Organizations: Structure, Form and Action. Harvard Business School Press, USA,

Nunnally, J. C. (1978). Psychometric Theory. McGraw-Hill, New York.

Oakland, J. S. and Porter, L. J. (1996). Total Quality Management: text with cases. Butterworth-Heinemann, Oxford.

Pagel, M. D., Erdly, W. W. and Becker, J. (1987). "Social Networks: We get by with (and in spite of) a little help from our friends." Journal of Personality and Social Psychology 53, :794 $-804$.

Podolny, J. M. and Baron, J. N. (1997). "Resources and Relationships: Social Networks and mobility in the workplace." American Sociological Review 62, :673 - 693.

Roberts, J. (2000). "From know-how to show-how? Questioning the role of information and communication technologies in knowledge transfer." Technology Analysis \& Strategic Management 12, 4:429-443.

Rolland, N. and Chauvel, D., Eds. (2000). Knowledge transfer in strategic alliances. Knowledge Horizons: The Present and the Promise of Knowledge Management. Butterworth Heinemann, Boston, MA.

Rotter, J. (1967). "A new scale for the measurement of interpersonal trust." Journal of Personality $35,: 651-665$.

Rousseau, D. M., Sitkin, S. B., Burt, R. S. and Camerer, C. (1998). "Not so different after all: A cross-discipline view of trust." Academy of Management Review 23, 3:393-404.

Smart, P. K., Brookes, N. J., Lettice, F. E., Backhouse, C. J. and Burns, N. D. (2000). "Working the boundaries in the automotive industry." Proceedings of the Institution of Mechanical Engineers, Part B: Journal of Engineering Manufacture Vol. 214, No. 10: pp. 941-946.

Smart, P. K., Brookes, N. J., Lettice, F. E., Backhouse, C. J. and Burns, N. D. (2001). "The Structure of Dynamic Organisations: Boundary Management in the Automotive Industry." International Journal of Production and Operations Management, .

Smart, P. K., Brookes, N. J., Lettice, F. E., Backhouse, C. J. and Burns, N. D. (2002). "A Boundary Based View of Product Development: A Feasibility Study." Proceedings of the Institution of Mechanical Engineers Part B: Journal of Engineering Manufacture Vol. 216, No. 1: pp. 1-12.

Stephenson, K. (1998). "What Knowledge Tears Apart, Networks Make Whole." Internal Communication Vol. 36, : pp. 22-25.

Svenke, M. and Goslinga, S. (2003). "The consequences of job insecurity for employers and unions: Exit, voice and loyalty." Journal of Economic and Industrial Democracy 24, 2:241.

Syan, C. S. (1994). "An Introduction to Concurrent Engineering". Concurrent engineering: concepts, implementation and practice. C. S. Syan and U. Menon. London, Chapman and Hall.

Tichy, N. M., Tushman, M. L. and Fombrun, C. (1979). "Social network analysis for organizations." Academy of Management Review 4, 4:507-519.

Tutton, S. (2003). Aerospace Services Homepage, http://www.aerospace.gknplc.com: .

Wasserman, S., Faust, K. and Iacobucci, D. (1994). Social Network Analysis: Methods and Applications (Structural Analysis in the Social Sciences), 
Wenger, E. C. and Snyder, W. M. (2000). "Communities of Practice: The Organizational Frontier." Harvard Business Review, .

Wheelwright, S. C. and Clark, K. B. (1992). Revolutionising product development: Quantum leaps in speed, efficiency and quality. Macmillan: The Free Press, New York.

Williamson, O. E. (1993). "Calculativeness, trust and economic organization.” Journal of Law and Economics 36, 2:453-486.

Yin, R. K. (1993). Applications of case study research. Sage Publications, Newbury Park; London.

Yin, R. K. (2003). Case study research: design and methods. Sage, Thousand Oaks, Calif.; London.

Zucker, L. G. (1986). "Production of trust: Institutional sources of economic structure, 18401920". Research in Organizational Behavior. B. Straw and C. L. Greenwich, CT, JAI Press. 8: 53-111. 